\title{
Association between Particulate Matter Exposure and Short-term Prognosis in Patients with Pneumonia
}

\author{
Chien-Chih Chen ${ }^{1+}$, Jyun-Bin Huang ${ }^{1+}$, Shih-Yu Cheng ${ }^{2}$, Kuan-Han Wu ${ }^{1}$, Fu-Jen Cheng ${ }^{*}$ \\ ${ }^{1}$ Department of Emergency Medicine, Kaohsiung Chang Gung Memorial Hospital, Chang Gung University College of \\ Medicine, Kaohsiung 83301, Taiwan \\ ${ }^{2}$ Department of Emergency Medicine, Yunlin Chang Gung Memorial Hospital, Yunlin 63861, Taiwan
}

\begin{abstract}
Particulate matter (PM) and other air pollutants are reportedly associated with both lung and systemic inflammation; however, an association between air pollutants and pneumonia outcomes has not been well established. Therefore, we evaluated the effect of air pollutants on the short-term outcomes of emergency department patients with pneumonia. We collected data on $\mathrm{PM}_{2.5}$ (aerodynamic diameter $<2.5 \mu \mathrm{m}$ ), $\mathrm{PM}_{10}$ (aerodynamic diameter $<10 \mu \mathrm{m}$ ), sulfur dioxide $\left(\mathrm{SO}_{2}\right)$, nitrogen dioxide $\left(\mathrm{NO}_{2}\right)$, and ozone from 11 air-quality monitoring stations in Kaohsiung City between January 1, 2008, and December 31, 2013. Medical records were extracted for non-trauma patients aged $>17$ years who had visited the emergency department with a principal diagnosis of pneumonia. In-hospital mortality and the association of air pollutant exposure with the need for invasive respiratory and/or vasopressor support (IRVS) within $72 \mathrm{~h}$ were evaluated. Interquartile range (IQR) increments of $\mathrm{PM}_{2.5}$ and $\mathrm{PM}_{10}$ were associated with an increased IRVS risk with odds ratios (ORs) of 1.211 (95\% confidence interval [CI], 1.031-1.419) and 1.194 (95\% CI, 1.020-1.394) on lag 1, respectively, and per-IQR increments of $\mathrm{NO}_{2}$ were associated with an increased IRVS risk with an OR of 1.146 (95\% CI, 1.004-1.308) on lag 2. IQR increments of PM $\mathrm{PM}_{2.5}$ and $\mathrm{NO}_{2}$ were associated with an increased in-hospital mortality risk with ORs of 1.202 (95\% CI, 1.100-1.429) and 1.175 (95\% CI, 1.014-1.360), respectively. During the warm season, IQR increments of $\mathrm{PM}_{2.5}, \mathrm{PM}_{10}$, and $\mathrm{NO}_{2}$ corresponded with an increased IRVS risk, with ORs of 1.333 (95\% CI, 1.078-1.644), 1.348 (95\% CI, 1.090-1.665), and 1.321 (95\% CI, 1.1011.585), respectively. For patients with pneumonia, $\mathrm{PM}_{2.5}, \mathrm{PM}_{10}$, and $\mathrm{NO}_{2}$ exposures were risk factors for a poor prognosis. Exposure effects appeared to be greater during the warm season. Regulations focused on $\mathrm{PM}_{2.5}, \mathrm{PM}_{10}$, and $\mathrm{NO}_{2}$ levels should be considered to improve patient outcomes.
\end{abstract}

Keywords: Particulate matter; Prognosis; Emergency department; Air pollution.

\section{INTRODUCTION}

Epidemiological studies have shown a positive association between pneumonia and short-term exposure to particulate matter (PM) (Ren et al., 2017; Cheng et al., 2019a). Fine particles (defined as PM with an aerodynamic diameter less than $2.5 \mu \mathrm{m} ; \mathrm{PM}_{2.5}$ ) are considered to pose greater health and regulatory challenges than larger particles, as epidemiological studies have recently suggested that they might exert a greater toxicity than larger particles (Qiu et al., 2014).

Pneumonia is a condition of lung inflammation that can lead to systemic inflammation. Toxicological studies have

\footnotetext{
${ }^{+}$These authors contributed equally to this work.

* Corresponding author.

Tel.: +886-975-056-646; Fax: +886-7-7317123-8415

E-mail address: a0953283092@yahoo.com.tw
}

shown that PM exposure may have hazardous effects on patients with pneumonia through the induction of both lung and systemic inflammation (Pope et al., 2016; Li et al., 2017).

Several multi-city studies have shown regional heterogeneity in the estimated effects of PM on health (Liu et al., 2017, 2018). Seasonal variation has also been found to modify the hazardous effects of PM (Cheng et al., 2015; Ueda et al., 2016). These regional and seasonal variations could be partially explained by differences in community characteristics, such as population density (Zeka et al., 2005), air-conditioning prevalence (Bell et al., 2009), and variation in PM components (Ueda et al., 2016).

Previous studies have focused on the association between PM and pneumonia-related emergency department (ED) admissions. In contrast, the association between PM and the short-term outcomes of patients with pneumonia has not been well established. The current study is the first to focus on the association between exposure to PM and other air pollutants and the short-term prognosis of pneumonia. This study included six years of pneumonia-related ED event data 
from a tertiary academic medical center in Southern Taiwan. These data were linked with air pollution and weather condition data to explore two specific objectives: (1) the associations of PM and other air pollutants with short-term pneumonia outcomes, and (2) the seasonality of the effect of $\mathrm{PM}$ on the short-term prognosis of patients with pneumonia.

\section{METHODS}

\section{Study Area and Population}

Situated on the southwest coast of Taiwan, Kaohsiung City is Taiwan's second-largest city. It has the largest commercial harbor and a population of approximately 2.77 million inhabitants. It is a major industrial center with numerous petrochemical and steel corporations. A retrospective observational study was conducted between January 1, 2008, and December 31, 2013, in an urban tertiary medical center with an average of 72,000 ED visits per year. The medical records of non-trauma patients aged $>17$ years who had visited the ED with a principal diagnosis of pneumonia (International Classification of Diseases, ninth revision [ICD-9]: 480-486) were extracted from the ED administrative database. Demographic factors, such as age and sex, and prognostic factors for pneumonia, such as preexisting hypertension, diabetes, malignancy, heart failure, respiratory disease, liver cirrhosis, chronic kidney disease, CURB-65 pneumonia severity score (confusion, serum urea, respiratory rate, blood pressure, and age $>65$ years), and history of cerebellar infarction, were collated from patient medical records (Lim et al., 2003). Approval for this study was provided by our hospital's institutional review board (no. 201701059B0C501). The study was performed in accordance with the ethical standards set forth in the 1964 Declaration of Helsinki and its later amendments. Formal consent was not required from subjects for this type of study.

\section{Pollutant and Meteorological Data}

In 1994, 11 air-quality monitoring stations were established in Kaohsiung City by the Taiwanese Environmental Protection Administration (EPA), a central governmental agency. The monitoring stations are fully automated and record hourly readings of $\mathrm{PM}_{10}$ and $\mathrm{PM}_{2.5}$ (using beta-ray absorption), nitrogen dioxide $\left(\mathrm{NO}_{2}\right)$ (using ultraviolet fluorescence), sulfur dioxide $\left(\mathrm{SO}_{2}\right)$ (using ultraviolet fluorescence), and ozone $\left(\mathrm{O}_{3}\right)$ (using ultraviolet photometry) levels. We obtained 24-houraverage levels of air pollutants from each monitoring station, as well as the addresses of patients with pneumonia from their medical records, and computer-matched patients to their nearest monitoring station. When the data from the nearest EPA monitoring site was missing, we used the data from the second-nearest EPA monitoring site. Daily information on the mean temperature and mean humidity was also collected from the monitoring stations. Missing data from air-quality monitoring stations accounted for less than $1 \%$ of the total data. We categorized the concentration of each air pollutant sampled on the same day a patient visited the ED as lag 0 . The concentration of each air pollutant sampled on the day before a patient visited the ED was categorized as lag 1, and so on. The results of previous investigations indicated that an increased number of hospital admissions for pneumonia were associated with higher ambient air pollutant levels on lag 0 to 3 (Qiu et al., 2014; Cheng et al., 2019b). Longer lag times have rarely been described. Therefore, a cumulative lag period of up to 3 days before an ED visit (i.e., the average air pollutant levels on the same day as the ED visit and up to 3 days before the ED visit) was used.

\section{Study Outcome}

The primary study outcome was the identification of patients who required invasive respiratory or vasopressor support (IRVS), defined as intubation for respiratory failure or vasopressor support prescribed for septic shock, within $72 \mathrm{~h}$ of ED presentation. IRVS was selected as the primary outcome because it provides a more objective assessment of critical illness than intensive care unit admission, which may be driven by factors other than illness severity (Chalmers et al., 2009). A window of $72 \mathrm{~h}$ was selected to limit the outcome to manifestations most likely related to a pneumonia episode rather than delayed nosocomial complications (Mandell et al., 2007).

\section{Statistics}

The results of the descriptive analyses of independent variables are reported as percentages or means \pm standard deviations. Independent variables were analyzed using the $\chi^{2}$ test, Mann-Whitney U test, and Student's t-test. The statistical significance of the relationship between the air pollutants and IRVS was analyzed using logistic regression to obtain odds ratios (ORs) and 95\% confidence intervals (CIs). A p-value $<0.05$ was considered statistically significant. SPSS version 25.0 (IBM Corp, Armonk, NY, USA) was used for all statistical analyses.

\section{RESULTS}

Over the course of the six-year study period, a total of 3985 patients visited our ED with pneumonia-related illnesses. In total, 607 patients were excluded from the analysis because they did not reside in the Kaohsiung City area; thus, our study group comprised 3378 patients. Overall, 379 patients $(11.2 \%)$ required IRVS within $72 \mathrm{~h}$ of hospital presentation, including 97 patients $(2.9 \%)$ who required both invasive respiratory and vasopressor support, 229 patients $(6.8 \%)$ who required respiratory support only, and 53 patients $(1.6 \%)$ who required vasopressor support only. The demographic characteristics of the group are listed in Table 1. Patients with older age $(p<0.001)$, diabetes $(p=$ $0.012)$, heart failure $(\mathrm{p}<0.001)$, renal insufficiency $(\mathrm{p}<$ $0.001)$, malignancy $(\mathrm{p}<0.001)$, and a higher CURB-65 score $(\geq 3)$ for pneumonia severity $(p<0.001)$ had a higher risk of requiring IRVS. Patients who required IRVS had higher $\mathrm{PM}_{2.5}(\mathrm{p}=0.031)$ and $\mathrm{PM}_{10}(\mathrm{p}=0.047)$ exposures on lag 1. Patients who required IRVS had higher in-hospital mortality rates $(\mathrm{p}<0.001)$.

\section{Air Pollutants and Meteorological Results}

A summary of daily mean concentrations of air pollutants and weather variables in Kaohsiung City during the study 
Table 1. Demographic characteristics of 3378 ED patients with pneumonia by IRVS category.

\begin{tabular}{|c|c|c|c|}
\hline \multirow{2}{*}{$\begin{array}{l}\text { Demographic characteristics of ED patients } \\
\text { with pneumonia }\end{array}$} & IRVS & No IRVS & \multirow{2}{*}{ p-value } \\
\hline & $\mathrm{N}=379$ & $\mathrm{~N}=2999$ & \\
\hline Male & 237 & 1919 & 0.657 \\
\hline Age & $71.2 \pm 15.0$ & $66.6 \pm 17.4$ & $<0.001$ \\
\hline Hypertension & 86 & 814 & 0.065 \\
\hline Diabetes & 92 & 566 & 0.012 \\
\hline Old stroke & 55 & 353 & 0.123 \\
\hline Parkinsonism & 15 & 81 & 0.165 \\
\hline Liver cirrhosis & 11 & 85 & 0.94 \\
\hline Hear failure & 48 & 187 & $<0.001$ \\
\hline Renal insufficiency & 65 & 186 & $<0.001$ \\
\hline Malignancy & 94 & 513 & $<0.001$ \\
\hline Leukemia & 4 & 49 & 0.393 \\
\hline CURB $65 \geq 3$ & 163 & 546 & $<0.001$ \\
\hline Respiratory disease & 73 & 632 & 0.413 \\
\hline In-hospital mortality & 112 & 212 & $<0.001$ \\
\hline \multicolumn{4}{|l|}{$\mathrm{PM}_{2.5}, \boldsymbol{\mu \mathrm { g } \mathrm { m } ^ { - 3 }}$} \\
\hline lag 0 & $45.9 \pm 21.4$ & $44.3 \pm 21.2$ & 0.152 \\
\hline lag 1 & $46.8 \pm 22.1$ & $44.3 \pm 21.2$ & 0.031 \\
\hline lag 2 & $46.7 \pm 21.7$ & $44.4 \pm 21.7$ & 0.058 \\
\hline lag 3 & $46.0 \pm 20.9$ & $44.7 \pm 21.6$ & 0.253 \\
\hline \multicolumn{4}{|l|}{$\mathrm{PM}_{10}, \mu \mathrm{g} \mathrm{m}^{-3}$} \\
\hline $\operatorname{lag} 0$ & $72.1 \pm 35.3$ & $73.3 \pm 35.7$ & 0.535 \\
\hline lag 1 & $82.3 \pm 37.0$ & $77.8 \pm 36.9$ & 0.047 \\
\hline $\operatorname{lag} 2$ & $82.1 \pm 36.9$ & $78.4 \pm 37.0$ & 0.067 \\
\hline lag 3 & $81.2 \pm 36.5$ & $78.9 \pm 36.4$ & 0.24 \\
\hline \multicolumn{4}{|l|}{$\mathrm{NO}_{2}, \mathbf{p p b}$} \\
\hline lag 0 & $20.1 \pm 9.0$ & $19.7 \pm 8.8$ & 0.318 \\
\hline lag 1 & $21.6 \pm 9.4$ & $20.8 \pm 9.0$ & 0.15 \\
\hline lag 2 & $21.9 \pm 9.4$ & $21.0 \pm 9.1$ & 0.053 \\
\hline lag 3 & $21.8 \pm 9.4$ & $21.0 \pm 9.0$ & 0.132 \\
\hline \multicolumn{4}{|l|}{$\mathrm{SO}_{2}, \mathbf{p p b}$} \\
\hline lag 0 & $7.3 \pm 4.1$ & $7.5 \pm 5.6$ & 0.605 \\
\hline lag 1 & $8.4 \pm 6.8$ & $7.9 \pm 5.9$ & 0.198 \\
\hline lag 2 & $8.3 \pm 6.1$ & $7.9 \pm 5.7$ & 0.156 \\
\hline lag 3 & $8.4 \pm 6.8$ & $8.0 \pm 5.7$ & 0.177 \\
\hline \multicolumn{4}{|l|}{$\mathrm{O}_{3}, \mathbf{p p b}$} \\
\hline lag 0 & $28.0 \pm 12.9$ & $29.4 \pm 13.6$ & 0.062 \\
\hline lag 1 & $28.3 \pm 12.5$ & $28.6 \pm 12.9$ & 0.606 \\
\hline $\operatorname{lag} 2$ & $28.8 \pm 12.5$ & $28.5 \pm 13.0$ & 0.682 \\
\hline lag 3 & $28.5 \pm 13.5$ & $28.7 \pm 13.0$ & 0.78 \\
\hline
\end{tabular}

ED: emergency department; IRVS: invasive respiratory and/or vasopressor support; PM: particulate matter; $\mathrm{NO}_{2}$ : nitrogen dioxide; $\mathrm{SO}_{2}$ : sulfur dioxide; $\mathrm{O}_{3}$ : ozone; CURB-65: CURB-65 pneumonia severity score (confusion, serum urea, respiratory rate, blood pressure, and age $>65$ years).

period is shown in Table 2. The average $\mathrm{PM}_{2.5}$ concentration over the study period was $43.0 \mu \mathrm{g} \mathrm{m}^{-3}$. There was seasonal variation in the concentrations of all air pollutants between the cold season (October to March) and warm season (April to September). $\mathrm{PM}_{2.5}, \mathrm{PM}_{10}, \mathrm{NO}_{2}, \mathrm{SO}_{2}$, and $\mathrm{O}_{3}$ levels were statistically significantly higher during the cold season $(\mathrm{p}<$ 0.001 ), and temperature and humidity levels were statistically significantly higher during the warm season $(\mathrm{p}<0.001)$.

\section{Association between Air Pollutant Exposure and IRVS}

In logistic regression models, after adjusting for age, diabetes, heart failure, renal insufficiency, malignancy, a higher CURB-65 score ( $\geq 3$ ), and meteorological factors such as temperature and humidity, $\mathrm{PM}_{2.5}, \mathrm{PM}_{10}$, and $\mathrm{NO}_{2}$ had a strong association with the risk of IRVS and inhospital mortality. As shown in Fig. 1(a), interquartile range (IQR) increments of $\mathrm{PM}_{2.5}$ and $\mathrm{PM}_{10}$ were associated with an increased IRVS risk, with ORs of 1.211 (95\% CI, 1.031$1.419)$ and 1.194 (95\% CI, 1.020-1.394) on lag 1, respectively. On lag 2, the levels of $\mathrm{PM}_{2.5}, \mathrm{PM}_{10}$, and $\mathrm{NO}_{2}$ were associated with an increased IRVS risk, with ORs of 1.187 (95\% CI, 1.013-1.389), 1.187 (95\% CI, 1.015-1.386), and 1.146 (95\% CI, 1.004-1.308), respectively. On lag 2, IQR increments of $\mathrm{PM}_{2.5}$ corresponded with an increased risk of in-hospital 
Table 2. Summary statistics for meteorological factors and air pollution in Kaohsiung, 2008-2013.

\begin{tabular}{|c|c|c|c|c|c|c|c|c|c|c|}
\hline & \multirow{2}{*}{ Minimum } & \multicolumn{3}{|c|}{ Percentiles } & \multirow{2}{*}{ Maximum } & \multirow{2}{*}{ Mean } & \multirow{2}{*}{$\begin{array}{l}\text { Warm season } \\
(\text { mean } \pm \mathrm{SD})\end{array}$} & \multirow{2}{*}{$\begin{array}{l}\text { Cold season } \\
(\text { mean } \pm \mathrm{SD})\end{array}$} & \multirow{2}{*}{$\mathrm{p}$-value } & \multirow{2}{*}{ IQR } \\
\hline & & $25 \%$ & $50 \%$ & $75 \%$ & & & & & & \\
\hline $\mathrm{PM}_{2.5}$ & 10.81 & 24.83 & 42.25 & 56.31 & 126.72 & 42.99422 & $30.3 \pm 14.7$ & $55.8 \pm 16.7$ & $<0.001$ & 31.47 \\
\hline $\mathrm{PM}_{10}$ & 14.69 & 44.28 & 71.92 & 97.20 & 581.96 & 74.07574 & $52.2 \pm 23.2$ & $96.0 \pm 31.1$ & $<0.001$ & 52.92 \\
\hline $\mathrm{NO}_{2}$ & 3.92 & 13.52 & 18.69 & 24.60 & 45.20 & 19.33997 & $14.4 \pm 4.5$ & $24.3 \pm 5.5$ & $<0.001$ & 11.08 \\
\hline $\mathrm{SO}_{2}$ & 2.02 & 5.07 & 6.40 & 8.02 & 17.23 & 6.684437 & $6.1 \pm 2.1$ & $7.2 \pm 2.1$ & $<0.001$ & 2.95 \\
\hline $\mathrm{O}_{3}$ & 3.51 & 18.90 & 27.87 & 37.36 & 74.60 & 28.97398 & $28.0 \pm 13.0$ & $30.0 \pm 11.7$ & $<0.001$ & 18.46 \\
\hline Temperature & 12.41 & 22.29 & 26.41 & 28.73 & 32.11 & 25.27048 & $28.2 \pm 1.9$ & $22.3 \pm 3.6$ & $<0.001$ & 6.44 \\
\hline Humidity & 43.97 & 69.98 & 74.16 & 78.14 & 95.32 & 74.11217 & $76.0 \pm 6.6$ & $72.2 \pm 7.3$ & $<0.001$ & 8.17 \\
\hline
\end{tabular}

SD: standard deviation; IQR: interquartile range; $\mathrm{PM}$ : particulate matter; $\mathrm{NO}_{2}$ : nitrogen dioxide; $\mathrm{SO}_{2}$ : sulfur dioxide; $\mathrm{O}_{3}$ : ozone.
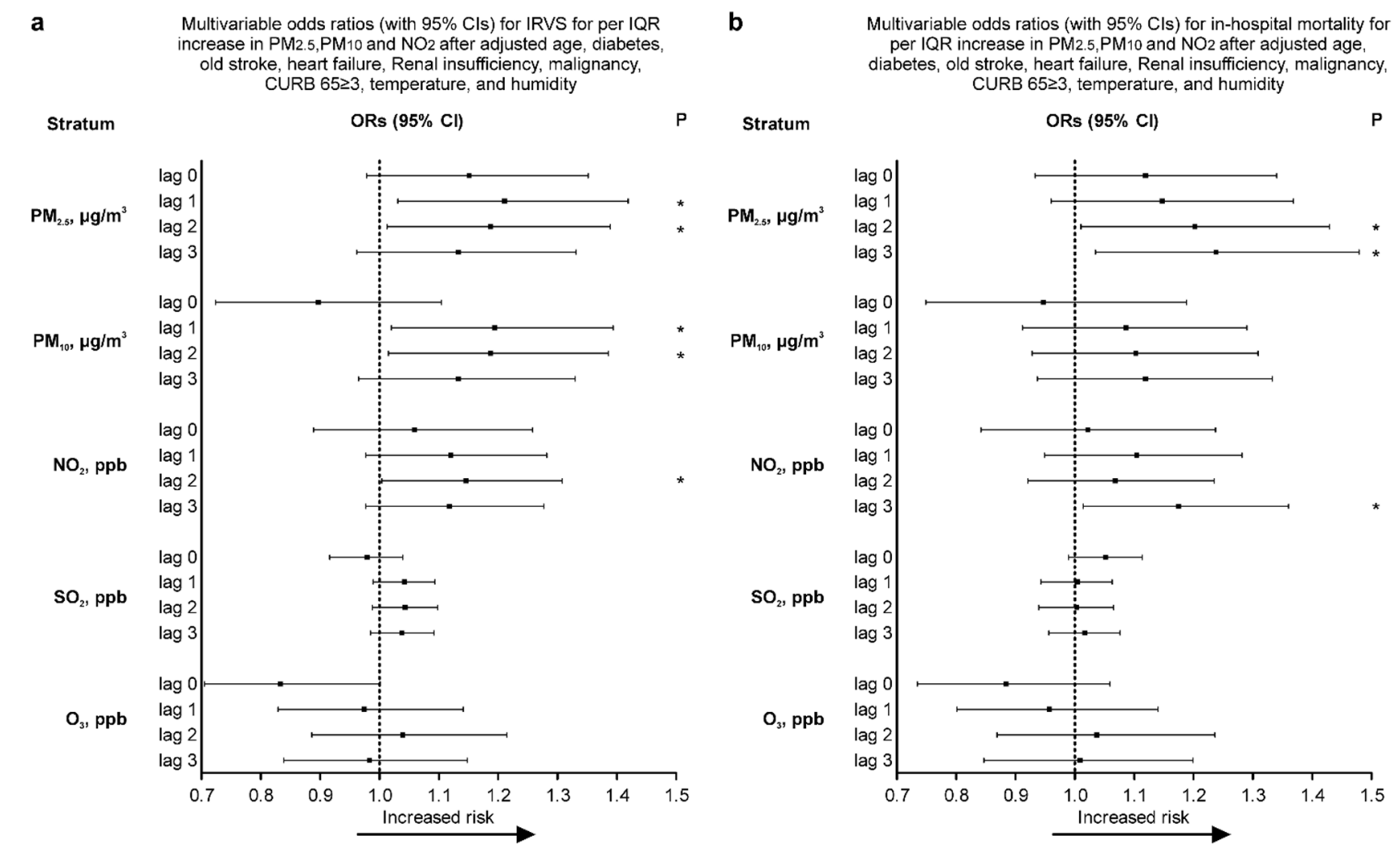

Fig. 1. Multivariate ORs ( $95 \%$ CIs) for (a) IRVS and (b) in-hospital mortality for per-IQR increases in $\mathrm{PM}_{2.5}, \mathrm{PM}_{10}, \mathrm{NO}_{2}$, $\mathrm{SO}_{2}$, and $\mathrm{O}_{3}$ after adjusting for age, diabetes, old stroke, heart failure, renal insufficiency, malignancy, CURB-65 ( $\geq 3$ ), temperature, and humidity.

mortality, with an OR of 1.202 (95\% CI, 1.010-1.429) (Fig. 1(b)). On lag 3, levels of $\mathrm{PM}_{2.5}$ and $\mathrm{NO}_{2}$ corresponded with an increased risk of in-hospital mortality, with ORs of 1.238 (95\% CI, 1.035-1.479) and 1.175 (95\% CI, 1.014 1.360), respectively. The ORs were not statistically significant for $\mathrm{O}_{3}$ or $\mathrm{SO}_{2}$, neither for IRVS nor in-hospital mortality.

Stronger associations were observed during the warm season. As shown in Fig. 2(a), IQR increments of $\mathrm{PM}_{10}$ corresponded with an increased IRVS risk on lag 1 during the warm season, with an OR of 1.249 (95\% CI, 1.009-1.542). On lag 2, $\mathrm{PM}_{2.5}, \mathrm{PM}_{10}$, and $\mathrm{NO}_{2}$ exposure corresponded with an increased IRVS risk during the warm season, with ORs of 1.333 (95\% CI, 1.078-1.644), 1.348 (95\% CI, 1.090 $1.665)$, and 1.321 (95\% CI, 1.101-1.585), respectively. On lag $3, \mathrm{NO}_{2}$ exposure corresponded with an increased IRVS risk during the warm season $(\mathrm{OR}=1.201 ; 95 \% \mathrm{CI}, 1.002-$ 1.439). As shown in Fig. 2(b), there was no statistically significant association between $\mathrm{PM}_{2.5}, \mathrm{PM}_{10}$, and $\mathrm{NO}_{2}$ and IRVS during the cold season. The ORs of $\mathrm{PM}_{2.5}$ and $\mathrm{PM}_{10}$ for in-hospital mortality risk were slightly higher during the warm season, but they did not achieve statistical significance (Figs. 2(c) and 2(d)).

\section{DISCUSSION}

In this study, we evaluated the effect of PM on the shortterm prognosis of ED patients with pneumonia and found that $\mathrm{PM}_{2.5}, \mathrm{PM}_{10}$, and $\mathrm{NO}_{2}$ may be associated with poor 
a

Stratum

$\mathrm{PM}_{2.5}, \mu \mathrm{g} / \mathrm{m}^{3}$

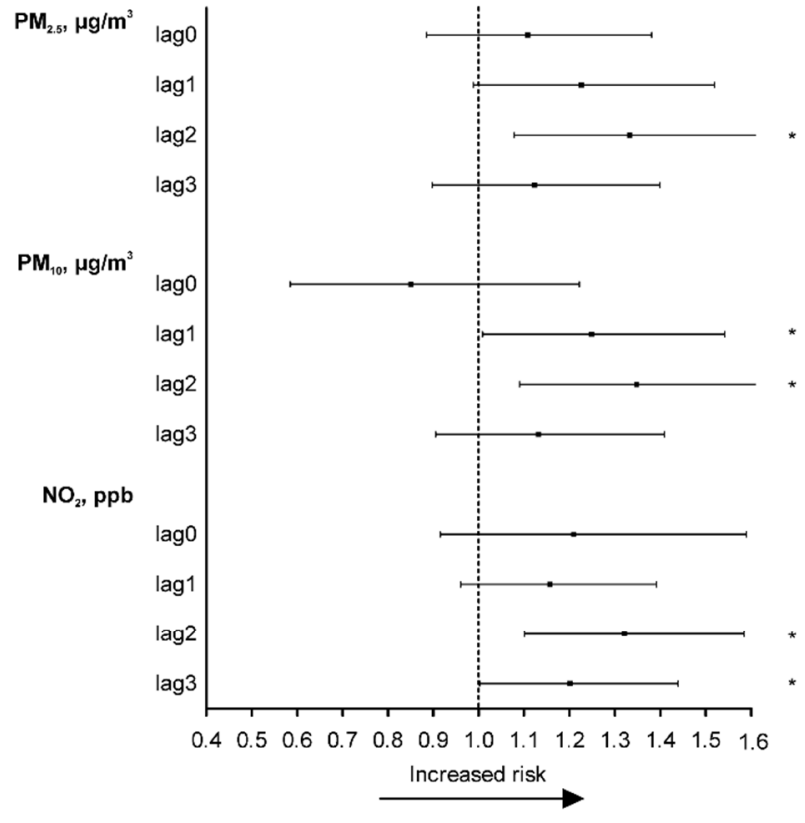

C

Stratum

$\mathrm{PM}_{2.5}, \mu \mathrm{g} / \mathrm{m}^{3}$

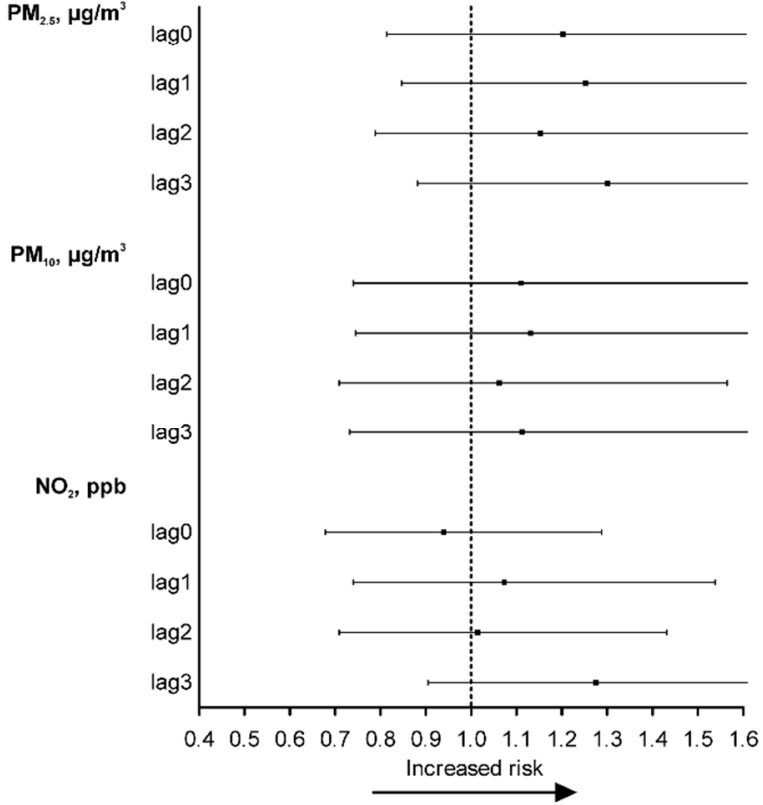

ultivariable odds ratios (with $95 \% \mathrm{Cls}$ ) for IRVS during warm season

ORs $(95 \% \mathrm{Cl})$ b

Stratum

$\mathrm{PM}_{2.5}, \mu \mathrm{g} / \mathrm{m}^{3}$

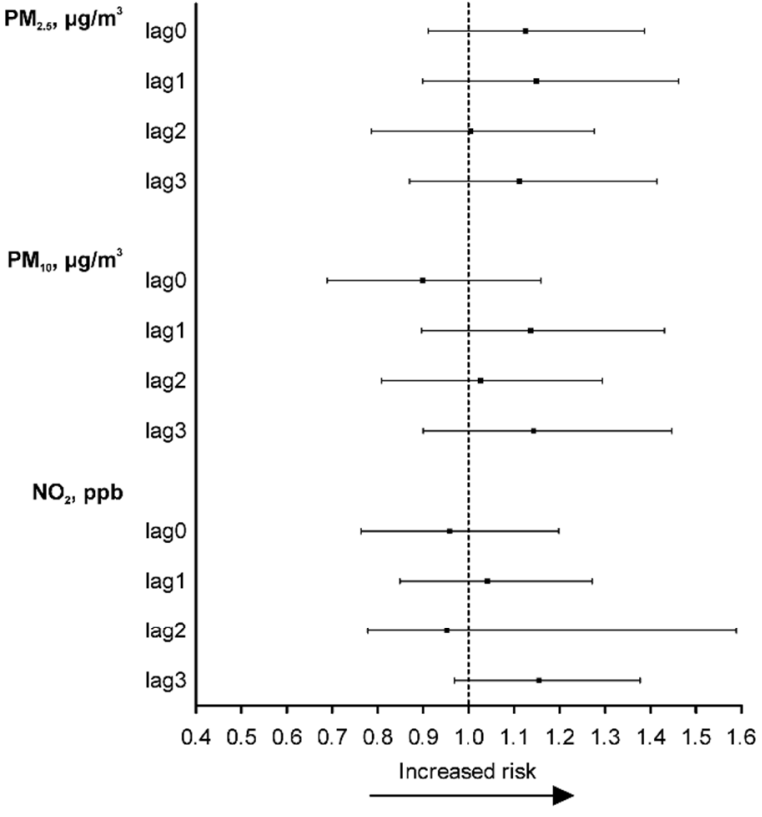

d

Stratum

$\mathrm{PM}_{2.5}, \mu \mathrm{g} / \mathrm{m}^{3}$

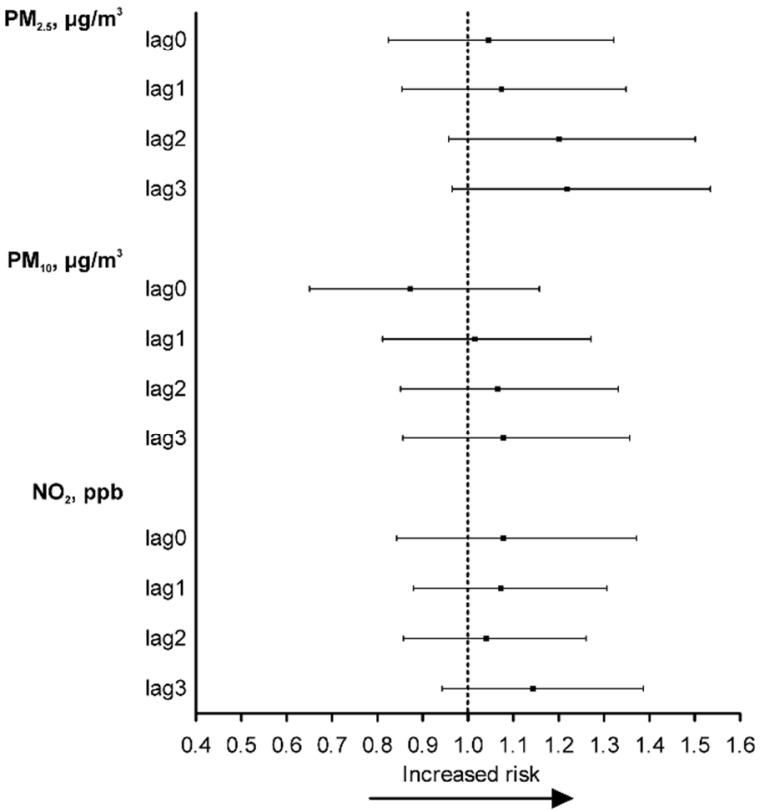

Fig. 2. Multivariate ORs ( $95 \%$ CIs) for IRVS for per-IQR increases in $\mathrm{PM}_{2.5}, \mathrm{PM}_{10}$, and $\mathrm{NO}_{2}$ during the (a) warm season and (b) cold season. Multivariate ORs $\left(95 \%\right.$ CIs) for in-hospital mortality for per-IQR increases in $\mathrm{PM}_{2.5}, \mathrm{PM}_{10}$, and $\mathrm{NO}_{2}$ during the (c) warm season and (d) cold season. Adjustments were made for age, diabetes, old stroke, heart failure, renal insufficiency, malignancy, CURB-65 ( $\geq 3)$, temperature, and humidity.

outcomes, especially during the warm season. Many recent epidemiological studies have reported that different air pollutants appear to have different health effects. $\mathrm{PM}_{2.5}$ was reported to be associated with out-of-hospital cardiac arrest (OHCA) (Kang et al., 2016), acute stroke (Huang et al.,
2016), respiratory diseases (Cheng et al., 2015; Haikerwal et al., 2016; Cheng et al., 2019b), respiratory deaths (Ren et al., 2017), and myocardial infarction (Weichenthal et al., 2016). $\mathrm{PM}_{10}$ was reported to be associated with OHCA (Kang et al., 2016), cardiovascular disease mortality (Liu et 
al., 2015), respiratory mortality (Wang et al., 2016), and hemorrhagic stroke (Han et al., 2016). $\mathrm{NO}_{2}$ has been associated with OHCA (Kang et al., 2016), cardiovascular disease mortality (Liu et al., 2015), and respiratory admissions (Fusco et al., 2001). In terms of pneumonia, $\mathrm{PM}_{2.5}, \mathrm{PM}_{10}$, and $\mathrm{NO}_{2}$ were reported to be associated with hospital admissions for pneumonia and ED visits (Qiu et al., 2014; Cheng et al., 2015; Cheng et al., 2019b). However, our study is the first to focus on the effects of air pollutants on pneumonia outcomes. We found that $\mathrm{PM}_{2.5}, \mathrm{PM}_{10}$, and $\mathrm{NO}_{2}$ were associated with a higher rate of IRVS and that $\mathrm{PM}_{2.5}$ and $\mathrm{NO}_{2}$ were associated with a higher risk of in-hospital mortality. Therefore, our findings showed that air pollutants, including $\mathrm{PM}_{2.5}, \mathrm{PM}_{10}$, and $\mathrm{NO}_{2}$, were associated with poor outcomes in patients with pneumonia.

Of the air pollutants we studied, PM was reported to have a greater negative effect on health on the basis of its higher toxicity compared with other pollutants (Qiu et al., 2014; Kang et al., 2016). PM has been shown to induce airway inflammation by triggering tumor protein p53 (TP53)dependent autophagy, pro-inflammatory cytokine release, and asthma-like airway inflammation (Xu et al., 2016; Ogino et al., 2017; Ramanathan et al., 2017). PM exposure has also been shown to be associated with systemic inflammation in various human studies (Hassanvand et al., 2017; Li et al., 2017). Short-term exposure to differently sized PM has been associated with various inflammation and coagulation blood markers (Hassanvand et al., 2017). $\mathrm{PM}_{10}$ exposure has been associated with elevated white blood cell (WBC) counts, as well as elevated interleukin (IL)-6 and Von Willebrand factor (vWF) levels, which are highly associated with systemic inflammation (Hassanvand et al., 2017). $\mathrm{PM}_{2.5}$ exposure has been associated with elevated WBC counts, as well as elevated C-reactive protein (CRP), tumor necrosis factor receptor 2, high sensitivity CRP, vWF, and IL-6 levels (Hassanvand et al., 2017; Li et al., 2017). In the present study, we found that PM exposure was associated with a higher risk of requiring IRVS among patients with pneumonia. This positive association is likely to be due to PM-related lung and systemic inflammation.

Some animal studies showed that $\mathrm{NO}_{2}$ exposure was associated with up-regulated changes in pro-inflammatory cytokines, reduced resistance to infectious agents, and altered alveolar macrophage function in the lungs (Chauhan et al., 1998; Rao, 2000; Ji et al., 2015). The association between $\mathrm{NO}_{2}$ and systemic inflammation is controversial. $\mathrm{NO}_{2}$ exposure has been shown to be associated with systemic inflammation with increased CRP, fibrinogen, and hepatocyte growth factor levels in patients with chronic obstructive pulmonary disease (Dadvand et al., 2014). Johannesson et al. (2014) reported no significant increase in biomarkers of inflammation and coagulation after $\mathrm{NO}_{2}$ exposure in healthy volunteers. Several studies have reported a positive association between $\mathrm{NO}_{2}$ levels and hospital admissions for pneumonia (Barnett et al., 2006; Cheng et al., 2007; Souza and Nascimento, 2016); however, the association between the severity of pneumonia and $\mathrm{NO}_{2}$ remains unclear. Our study showed that $\mathrm{NO}_{2}$ exposure was associated with a higher rate of IRVS and in-hospital mortality in patients with pneumonia. These results suggest that $\mathrm{NO}_{2}$ exposure might be associated with lung and systemic inflammation.

Many previous epidemiological studies have shown that the window for air pollution to affect health ranges from 0 to 3 days. Kojima et al. (2017) found that Asian dust was associated with acute myocardial infarction on lag 1; Kang et al. (2016) revealed that $\mathrm{PM}_{2.5}$ and $\mathrm{NO}_{2}$ were associated with OHCA on lag 1 and 2. For pneumonia, Qiu et al. (2014) found a positive relationship between $\mathrm{PM}_{2.5-10}$ and daily emergency hospital admissions on lag 0 to 3; and Cheng et al. (2019a) demonstrated an increased risk of $\mathrm{PM}_{2.5}$ and $\mathrm{NO}_{2}$ on pneumonia ED visit on lag 3. The findings of the present study were similar, and we found that $\mathrm{PM}_{2.5}, \mathrm{PM}_{10}$, and $\mathrm{NO}_{2}$ exposures on lag 1 to 3 were risk factors for poor prognosis in pneumonia patients. The different windows in which air pollution exposure affects health might be explained by the inflammatory response induced by air pollution. Hassanvand et al. (2017) found that $\mathrm{PM}_{2.5}$ exposure was associated with elevated IL- 6 and WBC on lag 1 in healthy young adults; in contrast, IL- 6 and WBC were elevated on lag 0 to 4 in older persons.

The health effects of air pollutants seemed to vary according to the season, but the precise seasonal effects remain controversial. Peng et al. (2015) explored seasonal patterns of the association between PM and mortality in 100 cities in the United States and showed that the effect of PM on mortality varied according to region. Stronger associations were observed during spring and summer in northern regions, whereas no clear seasonal variation was observed in southern regions (Peng et al., 2005). Another study found a stronger association between daily mortality and $\mathrm{PM}_{2.5}$ mass in the transitional seasons, spring and autumn (Ueda et al., 2016). Huang et al. reported that $\mathrm{PM}_{2.5}$ and $\mathrm{PM}_{10}$ were positively associated with hospital admissions for ischemic and hemorrhagic stroke on warm days $\left(>13.5^{\circ} \mathrm{C}\right)$ (Huang et al., 2016). Wang et al. (2016) found that the effects of $\mathrm{PM}_{10}$ on mortality due to pneumonia were stronger during spring and autumn, but Cheng et al. (2015) showed that higher levels of $\mathrm{PM}_{2.5-10}$ increased the risk of hospital admissions for respiratory diseases on cool days. Our study showed that $\mathrm{PM}_{2.5}, \mathrm{PM}_{10}$, and $\mathrm{NO}_{2}$ exposure had a greater effect on the need for IRVS in patients with pneumonia during the warm season. Some possible explanations for the association between seasonal change and health effects are that the concentrations of various PM components differ during different seasons and that these PM components have different effects on health; elemental carbon and organic carbon were found to be associated with cardiovascular mortality, and sulfate and nitrate were found to be associated with respiratory mortality (Ueda et al., 2016). Additionally, personal exposure levels may differ according to the season. More open windows during the warm season may contribute to higher air pollutant exposure, which would result in greater effects on health (Bell et al., 2009).

Previous studies have shown that age, sex, heart failure, stroke, malignancy, higher CURB-65 scores, and chronic renal insufficiency were risk factors for poor outcomes among patients with pneumonia (Mortensen et al., 2002; Yende et al., 2007; Johnstone et al., 2008). After adjusting 
for these factors, our study found that air pollutant exposure appears to be an independent risk factor for poor outcomes in patients with pneumonia. Regulations focusing specifically on $\mathrm{PM}_{2.5}, \mathrm{PM}_{10}$, and $\mathrm{NO}_{2}$ should be considered to improve air quality and the prognosis of patients with pneumonia.

\section{Limitations}

This study had several limitations. First, this study was conducted in a single tropical city in Southern Taiwan with a limited number of patients. This may limit the generalizability of our findings to other locations with different meteorological and ethnic characteristics. Second, the present study used ICD-9 codes 480-486 as inclusion criteria; some cases might have been missed if the diagnosis was not made in the ED. Furthermore, personal exposure data, such as air conditioning use and time spent outdoors, were not collected in this study which may have led to possible misclassification of exposure levels.

\section{CONCLUSION}

We found that $\mathrm{PM}_{2.5}, \mathrm{PM}_{10}$, and $\mathrm{NO}_{2}$ exposures were risk factors for a poor prognosis in patients with pneumonia and that the effects of these exposures were greater during the warm season. Regulations focusing specifically on reducing $\mathrm{PM}_{2.5}, \mathrm{PM}_{10}$, and $\mathrm{NO}_{2}$ levels should be considered to improve patient outcomes.

\section{REFERENCES}

Barnett, A.G., Williams, G.M., Schwartz, J., Best, T.L., Neller, A.H., Petroeschevsky, A.L. and Simpson, R.W. (2006). The effects of air pollution on hospitalizations for cardiovascular disease in elderly people in Australian and New Zealand cities. Environ. Health. Perspect. 114: 1018-1023.

Bell, M.L., Ebisu, K., Peng, R.D. and Dominici, F. (2009). Adverse health effects of particulate air pollution: Modification by air conditioning. Epidemiology 20: 682686.

Chalmers, J.D., Singanayagam, A. and Hill, A.T. (2009). ICU admission and severity assessment in communityacquired pneumonia. Crit. Care 13: 156.

Chauhan, A.J., Krishna, M.T., Frew, A.J. and Holgate, S.T. (1998). Exposure to nitrogen dioxide $\left(\mathrm{NO}_{2}\right)$ and respiratory disease risk. Rev. Environ. Health 13: 73-90.

Cheng, C.Y., Cheng, S.Y., Chen, C.C., Pan, H.Y., Wu, K.H. and Cheng, F.J. (2019a). Ambient air pollution is associated with pediatric pneumonia: A time-stratified casecrossover study in an urban area. Environ. Health 18: 77.

Cheng, F.J., Lee, K.H., Lee, C.W. and Hsu, P.C. (2019b). Association between particulate matter air pollution and hospital emergency room visits for pneumonia with septicemia: A retrospective analysis. Aerosol Air Qual. Res. 19: 345-354.

Cheng, M.F., Tsai, S.S., Wu, T.N., Chen, P.S. and Yang, C.Y. (2007). Air pollution and hospital admissions for pneumonia in a tropical city: Kaohsiung, Taiwan. $J$. Toxicol. Environ. Health A 70: 2021-2026.
Cheng, M.H., Chiu, H.F. and Yang, C.Y. (2015). Coarse particulate air pollution associated with increased risk of hospital admissions for respiratory diseases in a tropical city, Kaohsiung, Taiwan. Int. J. Environ. Res. Public. Health 12: 13053-13068.

Dadvand, P., Nieuwenhuijsen, M.J., Agustí, A., de Batlle, J., Benet, M., Beelen, R., Cirach, M., Martinez, D., Hoek, G., Basagaña, X., Ferrer, A., Ferrer, J., Rodriguez-Roisin, R., Sauleda, J., Guerra, S., Antó, J.M. and Garcia-Aymerich. J. (2014). Air pollution and biomarkers of systemic inflammation and tissue repair in COPD patients. Eur. Respir. J. 44: 603-613.

Fusco, D., Forastiere, F., Michelozzi, P., Spadea, T., Ostro, B., Arcà, M. and Perucci, C.A. (2001). Air pollution and hospital admissions for respiratory conditions in Rome, Italy. Eur. Respir. J. 17: 1143-1150.

Haikerwal, A., Akram, M., Sim, M.R., Meyer, M., Abramson, M.J. and Dennekamp, M. (2016). Fine particulate matter $\left(\mathrm{PM}_{2.5}\right)$ exposure during a prolonged wildfire period and emergency department visits for asthma. Respirology 21: 88-94.

Han, M.H., Yi, H.J., Ko, Y., Kim, Y.S. and Lee, Y.L. (2016). Association between hemorrhagic stroke occurrence and meteorological factors and pollutants. BMC Neurol. 16: 59.

Hassanvand, M.S., Naddafi, K., Kashani, H., Faridi, S., Kunzli, N., Nabizadeh, R., Momeniha, F., Gholampour, A., Arhami, M., Zare, A., Pourpak, Z., Hoseini, M. and Yunesian, M. (2017). Short-term effects of particle size fractions on circulating biomarkers of inflammation in a panel of elderly subjects and healthy young adults. Environ. Pollut. 223: 695-704.

Huang, F., Luo, Y., Guo, Y., Tao, L., Xu, Q., Wang, C., Wang, A., Li, X., Guo, J., Yan, A. and Guo, X. (2016). Particulate matter and hospital admissions for stroke in Beijing, China: Modification effects by ambient temperature. J. Am. Heart Assoc. 5: e003437.

Ji, X., Han, M., Yun, Y., Li, G. and Sang, N. (2015). Acute nitrogen dioxide $\left(\mathrm{NO}_{2}\right)$ exposure enhances airway inflammation via modulating $\mathrm{Th} 1 / \mathrm{Th} 2$ differentiation and activating JAK-STAT pathway. Chemosphere 120: 722 728.

Johannesson, S., Andersson, E.M., Stockfelt, L., Barregard, L. and Sallsten, G. (2014). Urban air pollution and effects on biomarkers of systemic inflammation and coagulation: A panel study in healthy adults. Inhalation Toxicol. 26: 84-94.

Johnstone, J., Eurich, D.T., Majumdar, S.R., Jin, Y. and Marrie, T.J. (2008). Long-term morbidity and mortality after hospitalization with community-acquired pneumonia: A population-based cohort study. Medicine 87: 329-334.

Kang, S.H., Heo, J., Oh, I.Y., Kim, J., Lim, W.H., Cho, Y., Choi, E.K., Yi, S.M., Do Shin, S., Kim, H. and Oh, S. (2016). Ambient air pollution and out-of-hospital cardiac arrest. Int. J. Cardiol. 203: 1086-1092.

Kojima, S., Michikawa, T., Ueda, K., Sakamoto, T., Matsui, K., Kojima, T., Tsujita, K., Ogawa, H., Nitta, H. and Takami, A. (2017). Asian dust exposure triggers acute myocardial infarction. Eur. Heart J. 38: 3202-3208. 
Li, W., Dorans, K.S., Wilker, E.H., Rice, M.B., Ljungman, P.L., Schwartz, J.D., Coull, B.A., Koutrakis, P., Gold, D.R., Keaney, J.F. Jr., Vasan, R.S., Benjamin, E.J. and Mittleman, M.A. (2017). Short-term exposure to ambient air pollution and biomarkers of systemic inflammation: The Framingham Heart Study. Arterioscler. Thromb. Vasc. Biol. 37: 1793-1800.

Lim, W.S., van der Eerden, M.M., Laing, R., Boersma, W.G., Karalus, N., Town, G.I., Lewis, S.A. and Macfarlane, J.T. (2003). Defining community acquired pneumonia severity on presentation to hospital: An international derivation and validation study. Thorax 58: 377-382.

Liu, H., Tian, Y., Xu, Y. and Zhang, J. (2017). Ambient particulate matter concentrations and hospitalization for stroke in 26 Chinese cities: A case-crossover study. Stroke 48: 2052-2059.

Liu, H., Tian, Y., Cao, Y., Song, J., Huang, C., Xiang, X., Li, M. and Hu, Y. (2018). Fine particulate air pollution and hospital admissions and readmissions for acute myocardial infarction in 26 Chinese cities. Chemosphere 192: 282-288.

Liu, Y., Chen, X., Huang, S., Tian, L., Lu, Y., Mei, Y., Ren, M., Li, N., Liu, L. and Xiang, H. (2015). Association between air pollutants and cardiovascular disease mortality in Wuhan, China. Int. J. Environ. Res. Public Health 12: 3506-3516.

Mandell, L.A. (2007). Infectious Diseases Society of America/American Thoracic Society consensus guidelines on the management of community-acquired pneumonia in adults. Clin. Infect. Dis. 44: S27-72.

Mortensen, E.M., Coley, C.M., Singer, D.E., Marrie, T.J., Obrosky, D.S., Kapoor, W.N. and Fine, M.J. (2002). Causes of death for patients with community-acquired pneumonia: Results from the Pneumonia Patient Outcomes Research Team cohort study. Arch. Intern. Med. 162: 1059-1064.

Ogino, K., Nagaoka, K., Okuda, T., Oka, A., Kubo, M., Eguchi, E. and Fujikura, Y. (2017). $\mathrm{PM}_{2.5}$-induced airway inflammation and hyperresponsiveness in $\mathrm{NC} / \mathrm{Nga}$ mice. Environ. Toxicol. 32: 1047-1054.

Peng, R.D., Dominici, F., Pastor-Barriuso, R., Zeger, S.L. and Samet, J.M. (2005). Seasonal analyses of air pollution and mortality in 100 US cities. Am. J. Epidemiol. 161: 585-594.

Qiu, H., Tian, L.W., Pun, V.C., Ho, K.F., Wong, T.W. and $\mathrm{Yu}$, I.T. (2014). Coarse particulate matter associated with increased risk of emergency hospital admissions for pneumonia in Hong Kong. Thorax 69: 1027-1033.

Ramanathan, M. Jr., London, N.R. Jr., Tharakan, A. Surya, N. Sussan, T.E., Rao, X., Lin, S.Y., Toskala, E.,
Rajagopalan, S. and Biswal, S. (2017). Airborne particulate matter induces nonallergic eosinophilic sinonasal inflammation in mice. Am. J. Respir. Cell Mol. Biol. 57: 59-65.

Rao, K.M. (2000). Molecular mechanisms regulating iNOS expression in various cell types. J. Toxicol. Environ. Health Part B 3: 27-58.

Ren, M., Fang, X., Li, M. Sun, S., Pei, L., Xu, Q., Ye, X. and Cao, Y. (2017). Concentration-response relationship between $\mathrm{PM}_{2.5}$ and daily respiratory deaths in China: A systematic review and metaregression analysis of timeseries studies. Biomed. Res. Int. 2017: 5806185.

Souza, L.S. and Nascimento, L.F. (2016). Air pollutants and hospital admission due to pneumonia in children: A time series analysis. Rev. Assoc. Med. Bras. 62: 151-156.

Ueda, K., Nitta, H., Ono, M. and Takeuchi, A. (2016). Associations between fine particulate matter components and daily mortality in Nagoya, Japan. J. Epidemiol. 26: 249-257.

Wang, X., Guo, Y., Li, G., Zhang, Y., Westerdahl, D., Jin, X., Pan, X. and Chen, L. (2016). Spatiotemporal analysis for the effect of ambient particulate matter on causespecific respiratory mortality in Beijing, China. Environ. Sci. Pollut. Res. Int. 23: 10946-10956.

Weichenthal, S., Lavigne, E., Evans, G., Pollitt, K. and Burnett, R.T. (2016). Ambient $\mathrm{PM}_{2.5}$ and risk of emergency room visits for myocardial infarction: Impact of regional $\mathrm{PM}_{2.5}$ oxidative potential: A case-crossover study. Environ. Health 15: 46.

Xu, X., Wang, H., Liu, S., Xing, C., Liu, Y., Aodengqimuge, Zhou, W., Yuan, X., Ma, Y., Hu, M., Hu, Y., Zou, S., Gu, Y., Peng, S., Yuan, S., Li, W., Ma, Y. and Song, L. (2016). TP53-dependent autophagy links the ATR-CHEK1 axis activation to proinflammatory VEGFA production in human bronchial epithelial cells exposed to fine particulate matter $\left(\mathrm{PM}_{2.5}\right)$. Autophagy 12: 1832-1848.

Yende, S., Angus, D.C., Ali, I.S., Somes, G., Newman, A.B., Bauer, D., Garcia, M., Harris, T.B. and Kritchevsky, S.B. (2007). Influence of comorbid conditions on long-term mortality after pneumonia in older people. J. Am. Geriatr. Soc. 55: 518-525.

Zeka, A., Zanobetti, A. and Schwartz, J. (2005). Short term effects of particulate matter on cause specific mortality: Effects of lags and modification by city characteristics. Occup. Environ. Med. 62: 718-725.

Received for review, June 8, 2019 Revised, October 9, 2019 Accepted, December 7, 2019 